\title{
THE GROSS ANATOMY OF THE NERVOUS SYSTEM OF Bothriurus bonariensis (L. C. KOCH, 1842) (SCORPIONES, BOTHRIURIDAE)
}

\author{
HORN, A. C. M. and ACHAVAL, M. \\ Laboratório de Histofisiologia Comparada, Departamento de Ciências Morfológicas, Instituto de Ciências Básicas da \\ Saúde, Universidade Federal do Rio Grande do Sul, Av. Sarmento Leite, 500, CEP 9000-170, Porto Alegre, Brazil \\ Correspondence to: Ângelo Cássio Magalhães Horn, Laboratório de Histofisiologia Comparada, \\ Departamento de Ciências Morfológicas, Instituto de Ciências Básicas da Saúde, Universidade Federal do Rio \\ Grande do Sul, Av. Sarmento Leite, 500, CEP 9000-170, Porto Alegre, Brazil, e-mail: angelocmh@terra.com.br \\ Received January 18, 2001 - Accepted May 10, 2001 - Distributed May 31, 2002
}

(With 2 figures)

\begin{abstract}
The nervous system of the order Scorpiones appears to have a common organizational structure. The combination of an anatomical study using methylene blue as the contrast medium together with a histological analysis using hematoxylin-eosin and Heindenhain's iron hematoxylin techniques permitted the identkfication of a large number of nerves in B. bonariensis. Many of these are also present in a variety of other species of scorpions, belonging to distinct families of the order Scorpiones. Nevertheless, two pairs of nerves from $B$. bonariensis originating in the cheliceral ganglion, one pair of esophageal nerves and one pair of nerves from the aortic arch, appear to diverge from this basic organization. They have not been previously described, nor have any equivalents been reported in research on other scorpion species, in which the current homological criteria have been employed.
\end{abstract}

Key-words: scorpion, Bothriurus, nervous system, ganglia, anatomy.

\section{RESUMO}

\section{Anatomia do sistema nervoso de Bothriurus bonariensis (L. C. KOCH, 1842)} (Scorpiones, Bothriuridae)

O sistema nervoso da ordem Scorpiones parece apresentar um plano comum de organização. Uma abordagem anatômica, utilizando o azul de metileno como meio contrastante para o tecido nervoso, e histológica, por intermédio das técnicas da hematoxilina-eosina e hematoxilina férrica de Heindenhain, permitiu identificar um grande número de nervos em $B$. bonariensis também presentes em diversas outras espécies de escorpiões, pertencentes a famílias distintas da ordem Scorpiones. Contudo, 2 pares de nervos de $B$. bonariensis com origem no gânglio queliceral, o par de nervos esofagianos e o par de nervos dos arcos aórticos, parecem divergir desse plano comum, visto não terem sido descritos anteriormente nem possuírem equivalentes em outras espécies de escorpiões pelos critérios de homologia utilizados.

Palavras-chave: escorpião, Bothriurus, sistema nervoso, gânglios, anatomia.

\section{INTRODUCTION}

As the oldest known group of arachnids (Stockwell, 1989; Sissom, 1990), scorpions have a morphologically primitive nervous system (NS) in which the ancestral organization has been preserved (Polis, 1990; Root, 1990). This basic layout consists of an anterior cephalothoracic mass di- vided into a dorsal supra-esophageal ganglion and a ventral sub-esophageal ganglion, joined by a pair of circumesophageal commissures as well as a long double ventral nerve cord that originates in this cephalothoracic mass and extends posteriorly. The latter is composed of seven free ganglia joined longitudinally by connectives and laterally by commissures (Millot \& Vachon, 1949; Hjelle, 1990). 
Comprehensive anatomical descriptions of the NS of scorpions have been completed for just a few species, representing only a small proportion of the families belonging to the order Scorpiones. Such descriptions are limited to Centruroides $s p$. (Buthidae) (McClendon, 1904); Uroctonus mordax (Vejovidae) (Henry, 1949); Heterometrus fulvipes (Scorpionidae) (Babu, 1965); and Tityus serrulatus (Buthidae) (Lucas et al., 1965).

The aim of this study was to describe the gross anatomy of the NS of B. bonariensis and compare the findings obtained with those in the literature for other species.

\section{MATERIAL AND METHODS}

Adult scorpions of both sexes of the species Bothriurus bonariensis (C. L. Koch, 1842) (Scorpiones, Bothriuridae) were used. The animals were collected in the counties of Porto Alegre (RS) and Barra do Ribeiro (RS), transferred to the laboratory, and kept in individual terrariums. The specimens were fed once a week on larvae of Tenebrio molitor.

In loco anatomical analysis of the NS of $B$. bonariensis was made of in twelve animals. They were anesthetized with chloroform and dissected using different procedures.

A group of six animals had the prosomal and mesosomal pleurites perfurated, after which they were placed on Petry dishes and fixed by immersion in the following solution: $12 \mathrm{ml}$ formalin, $30 \mathrm{ml} \mathrm{95 \%} \mathrm{alcohol,} 2 \mathrm{ml}$ glacial acetic acid, and $56 \mathrm{ml}$ of distilled water (Sissom et al., 1990). They were then washed in $50 \%$ alcohol and stored in $80 \%$ alcohol. In order to perform the anatomical study, the carapace, tergites, dorsal surface of the post-abdominal rings, dorsal surface of the telson, and tissue adjacent to the central nervous system (CNS) and main nerves were removed.

Six animals were taken to the dissection chamber, placed in $80 \%$ alcohol, and dissected until the main nerves of the CNS were exposed. The nerve tissue was washed in tap water and, later, in a saline solution. A methylene blue solution was applied and the tissue was then fixed according to Bethe (Ramón y Cajal \& de Castro, 1972), using 10\% ammonium molibdatum at $4{ }^{\circ} \mathrm{C}$ without previous washing. Finally, it was washed in distilled water and stored in $80 \%$ alcohol. The material was observed under a stereoscopic microscope (Wild) and photographed.
The twenty-one animals used in the histological study were anesthetized with chloroform and dissected on a paraffin plate with the aid of a stereoscopic microscope (Wild). The CNS was carefully removed, fixed in Bouin's solution or in $10 \%$ formalin, and embedded in paraffin. The CNS was then serially sectioned $(5-10 \mu \mathrm{m})$ along three different planes: sagittal, horizontal, and transverse, with a microtome (Leitz). The sections were stained using either Heindenhain's iron hematoxylin or hematoxylin-eosin techniques (Romeis, 1928). The slides were examined using a Nikon Optiphot-2 microscope.

\section{RESULTS}

The nomenclature used to describe the external morphology in this paper is that originally established by Stahnke (1970). The terminology used to name the structures of the NS is adapted from the work of Babu (1965).

\section{General aspect and the regions of the CNS}

The CNS of B. bonariensis consists of a large anterior ganglionic mass located in the cephalothoracic region of the animals' body and known as the cephalothoracic mass, together with a long ventral nerve cord, almost exclusively opisthosomal, that extends from the most posterior region of the cephalothorax to the division between the fourth and fifth segment of the metasoma (Fig. 1). Within the cephalothoracic mass, it is possible to distinguish two regions: one dorsal, located above and laterally to the circum-esophageal channel called the supra-esophageal ganglion; and one ventral, found below the same channel, referred to as the sub-esophageal ganglion (Figs. 1 and 2).

\section{The supra-esophageal ganglion}

The supra-esophageal ganglion of $B$. bonariensis is located in the anterior and median region of the cephalothorax (Fig. 1). In relation to the cephalo-caudal axis, it is directly ventral to the pair of median eyes of the dorsal carapace and can be divided into two distinct parts. One is known as the protocerebrum (brain) and the other, the cheliceral ganglion (Fig. 2). However, there is no external evidence of such a division.

The protocerebrum corresponds to the most dorsal portion of the supra-esophageal ganglion and is more voluminous than the cheliceral ganglion. 


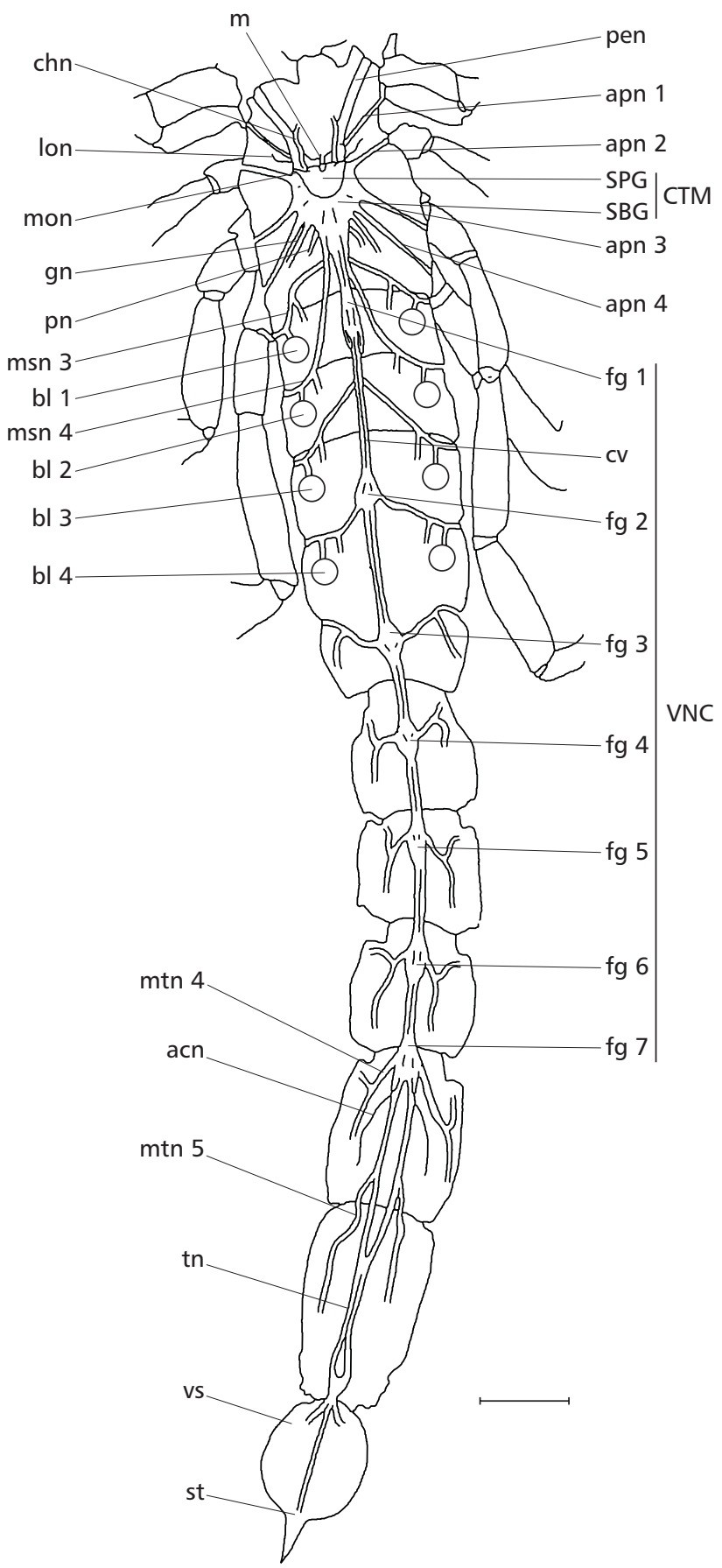

Fig. 1 - Schematic representation of the central nervous system and main nerves of Bothriurus bonariensis observed dorsally. A series of nerves arise from the anterior region of the cephalothoracic mass and proceed to the prosoma and part of the opisthosoma. The ventral nerve cord shows seven free ganglia (gl 1-7), which innervate the remaining opisthosoma: acn (alimentar channel nerves); apn 1-4 (ambulatory nerves 1-4); bl 1-4 (book lungs 1-4); chn (cheliceral nerve); CTM (cephalothoracic mass); cv (connectives); fg 1-7 (free ganglia 1-7); gn (genital nerve); msn 3-4 (third and fourth mesosomatic segmental nerves); lon (lateral optic nerve); mon (median optic nerve); mtn 4-5 (fourth and fifth metasomatic segmental nerves); pen (pedipalpal nerve); pn (pectinal nerve); rn (rostral nerve); SBG (suboesophageal ganglion); SPG (supra-esophageal ganglion); st (sting); tn (telsonic nerves); VNC (ventral nervous cord); vs (vesicle). Bar: $2 \mathrm{~mm}$. 


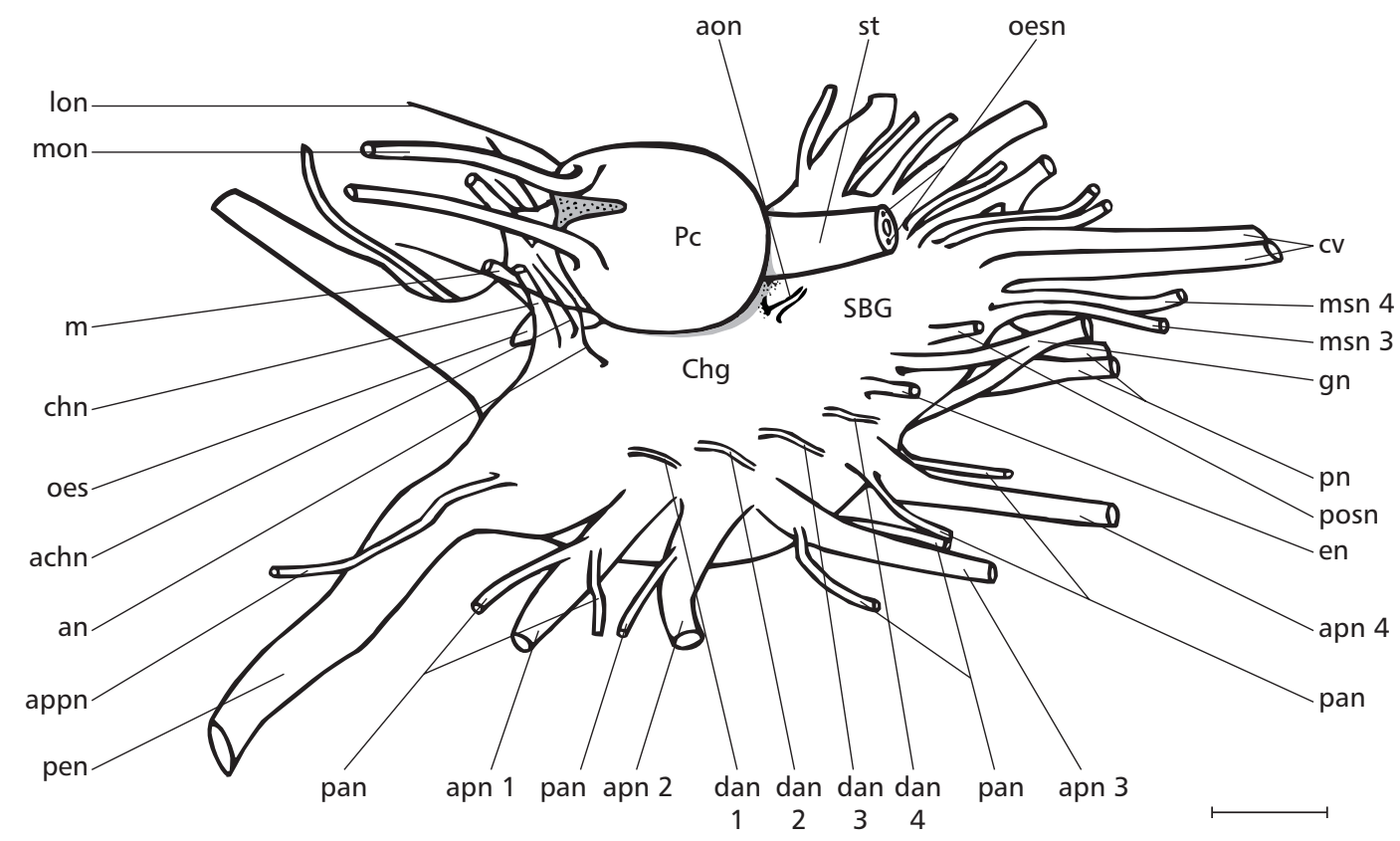

Fig. 2 - Schematic representation of the cephalothoracic mass of Bothriurus bonariensis observed lateral-dorsally. The cephalothoracic mass can be divided in the supra-esophageal ganglion, formed by the protocerebrum $(\mathrm{Pc})$ and cheliceral ganglion (Chg) and the sub-esophageal ganglion (SBG): achn (accessory cheliceral nerve); an (accessory nerves); aon (aortic arch nerve); apn 1-4 (ambulatory nerves 1-4); appn (accessory pedipalpal nerves); chn (cheliceral nerve); cv (connectives); dan 1-4 (dorsal ambulatory nerves 1-4); en (ephemeral nerve); gn (genital nerve); lon (lateral optic nerves); mon (median optic nerve); msn 3-4 (third and fourth mesosomatic segmental nerves); oes (oesophagus); oesn (oesophageal nerves); pan (pedal accessory nerves); pen (pedipalpal nerves); pn (pectinal nerve); posn (posterior nerve); st (stomach); rn (rostral nerve). Bar: $500 \mu \mathrm{m}$.

Viewed dorsally, the protocerebrum is rounded to triangular in shape. In the anterior region, it is possible to distinguish two anterior optic lobes due to the presence of a deep furrow that separating them bilaterally. Two pairs of single nerves originate from the protocerebrum: the median optic nerves and the lateral optic nerves (Fig. 2).

The pair of median optic nerves had the largest diameter $(71 \mu \mathrm{m})$ of the nerves found in the protocerebrum. They emerge dorsally from the lateral boundaries of each of the two optic lobes (Fig. 2), approximating the median line as they follow their trajectory to the base of the median eyes. On the other hand, the lateral optic nerves had an average diameter of $50 \mu \mathrm{m}$. They arise from the frontolateral surface of the protocerebrum (Fig. 2), closer to the median line of the animal body than are the median optic nerves. These long thin nerves extend toward the anterior vertices of the cephalothoracic carapace, cross the cheliceral musculature and divide into three small branches before penetrating the base of each of the three lateral eyes.

The cheliceral ganglion consists of a mass of nervous tissue located at the ventral portion of the supra-esophageal ganglion of B. bonariensis, which is found surrounding the circum-esophageal channel (Fig. 2). As occurs with the two portions of the supra-esophageal ganglion, it is difficult to distinguish the division between the ventral region of the cheliceral ganglion and the dorsal region of the sub-esophageal ganglion. Five pairs of nerves together with a single nerve were observed originating from the cheliceral ganglion; they were: the cheliceral nerves, accessory cheliceral nerves, accessory nerves, rostral nerve, aortic arch nerves; and esophageal nerves (Fig. 2).

Due mainly to their large diameter (average $83 \mu \mathrm{m})$, the cheliceral nerves were the easiest to visualize in the cheliceral ganglion. They arise laterally to the anterior region of cheliceral ganglion, 
emerging almost at the same level of the anterior opening of the circum-esophageal channel, proceed dorsally, incline, and finally penetrate the cheliceral muscle masses. Following the trajectory of this nerve it was also possible to observe dorsally the cheliceral artery, which terminates in the middle of the cheliceral muscle tissue.

Exactly dorsal to the cheliceral artery and next to the cheliceral nerves were observed a second pair of nerves, known as the accessory cheliceral nerves (Fig. 2), that terminate in the middle of the dorsal cheliceral musculature. These nerves originate laterally from the anterior surface of the cheliceral ganglion, below the lateral optic nerves and above the cheliceral nerves, being medial in relation to the former and lateral in relation to the latter. Before reaching the cheliceral musculature this pair of nerves branches once, forming a single thick branch (average $62 \mu \mathrm{m}$ ) and thinner lateral branch (average $20 \mu \mathrm{m})$.

The accessory nerves originate at the lateral and anterior wall of the cheliceral ganglion of B. bonariensis, directly below the cheliceral nerves (Fig. 2). Although these nerves advance in the direction of the cheliceraes, their termination could not be seen in these organs or in any other surrounding tissue.

The single rostral nerve (diameter, $80 \mu \mathrm{m}$ ) emerges from the anterior and median region of the cheliceral ganglion, immediately above the circum-esophageal channel (Fig. 2). It proceeds anteriorly over the roof of the pharyngeal sac, which is covered with a series of striated muscles oriented perpendicularly to the long axis of the nerve. Although no point of contact was observed between the rostral nerve and the muscle strands, the two structures were in close proximity throughout the trajectory of the nerve over the dorsal wall of the pharynx. At the anterior limit of the pharyngeal sac, the rostral nerve forks. One branch inclines vertically and continues on attached to the anterior wall of the pharyngeal sac, while the other continues in a cephalic direction, penetrating into the rostral region of the carapace.

The aortic arch nerves ( $39 \mu \mathrm{m}$ in diameter) consist of a small pair of nerves located on both sides of the base of the cheliceral ganglion, ventral to the posterior opening of the circum-esophageal channel (Fig. 2). From the posterior surface of the cheliceral ganglion, these two nerves follow a short trajectory, curving round the aortic arches and penetrating, latero-posteriorly into their walls. As a result, large masses of nerve tissue are visible on the posterior surface of the inner wall of the two aortic arches. These large masses branch dorsally and ventrally, reaching the upper portion of the aortic arch and the initial portions of the thoracic sinus, respectively.

A pair of small nerves, each with an average diameter of $40 \mu \mathrm{m}$, known as the esophageal nerves, emerge from the anterior and dorsal regions of the circum-esophageal channel wall, on either side of the cheliceral ganglion. These nerves proceed caudally, penetrating the wall of the esophagus and thereafter locating themselves in the connective tissue found around the striated muscular layer of the organ. As this pair of nerves advances within the walls of the esophagus (Fig. 2) towards the initial and median regions of the stomach, fine nerve branches appear which terminate in the form of diminutive ovoid bodies on the muscular strands.

\section{Sub-esophageal ganglion}

The sub-esophageal ganglion of $B$. bonariensis, which corresponds to the ventral portion of the cephalothoracic mass, is the most voluminous structure of the CNS (Figs. 1 and 2). It has a clear metamerism evidenced by the nerve segmentation and metameric character of the arterial elements of the vascular system, which is composed of nine neuromeres or pairs of ganglia. The most caudal portion of this composite ganglion visibly proceeds through the neural channel, formed by the main endosternite. Crossing the sub-esophageal ganglion dorso-ventrally along the median line, eight single metameric arteries, plus a ninth last artery, contouring its caudal extremity can be observed. These arteries terminate in a small calibre ventral vessel, known as the sub-neural artery, that runs along the entire ventral surface of the sub-esophageal ganglion.

A series of segmentary nerves originate from the sub-esophageal ganglion and innervate the prosoma and initial portions of the mesosoma. They include the pedipalpal, accessory pedipalpal, ambulatory, accessory pedal, dorsal ambulatory, ephemeral, genital, posterior, pectinal, and the third and fourth mesosomatic segmental nerves, together with a pair of connectives leading to the ventral nervous cord (Figs. 1 and 2).

The pedipalpal nerves originate in the most anterior part of the sub-esophageal ganglion of $B$. bonariensis (Figs. 1 and 2). They travel towards 
the front and slightly to the sides, penetrate the interior of the pedipalps, emitting small branch nerves to the surrounding musculature as they traverse the various parts of this structure. They are easily identified because they have the largest diameter $(305 \mu \mathrm{m})$ of all nerves in the NS of this animal. A small pair of dorso-lateral nerves are found close to their base, the pedipalpal accessory nerves (Fig. 2), which branch intensely within the musculature of the proximal articles of the pedipalps.

Posterior to the pedipalpal nerves, four pairs of large nerves are seen originating laterally from the sub-esophageal ganglion and then penetrating and traversing the four pairs of walking legs. They are the ambulatory nerves 1-4 respectively (Figs. 1 and 2). The smallest diameter nerve (average $123 \mu \mathrm{m})$ serves the first pair of legs and is turned slightly frontward; the nerves of the third and fourth pairs of legs have the largest diameters, $170 \mu \mathrm{m}$ and $175 \mu \mathrm{m}$ respectively, and can be seen oriented in a caudal direction. Dorsal and anterior or dorsal and posterior to these four pairs of nerves and very close to their point of origin, various small nerves can be found that emit their branches directly into the walking legs. These small nerves, that are peripheral to the ambulatory nerves 1-4, are known as the accessory pedal nerves (Fig. 2). Despite being difficult to locate and identify, in B. bonariensis two pairs were observed for the first set of ambulatory nerves, one pair for the second, and two pairs each for the third and fourth sets of ambulatory nerves.

Located between the 1-4 ambulatory nerves and the opening of the metameric arteries, in the dorso-lateral region of the suboesophageal ganglion, four small pairs of nerves were observed, placed slightly frontward in relation to the ambulatory nerves. These nerves arise in the direction of the cephalothoracic shield of the prosoma and are called the dorsal ambulatory nerves (Fig. 2). Despite their clear dorsal direction and the slight caudal inclination, their trajectory could not be followed nor, consequently, the structures innervated by this set of nerves identified.

In the caudal portion of the sub-esophageal ganglion of $B$. bonariensis, immediately following the group of neuromeres associated with the innervation of the pedipalps and ambulatory legs, there was a pair of dorsal nerves, known as the ephemeral nerves (Fig. 2). Due to the difficulty in identifying them in most of the animals observed, and despite a visible caudal inclination in species having these nerves, it proved impossible to identify the region that they innervate.

Two pairs of nerves are found posteriorly to the ephemeral nerves, one dorso-lateral the other ventro-lateral, known as the genital nerves (Fig. 2). Immediately after emerging from the sub-esophageal ganglion, these caudally inclining nerves join to form a single pair of nerves oriented towards the lateral walls of the animal body (Fig. 1). Before reaching the lateral walls, this pair of nerves forks. The narrower inner fork implants itself in the paraxial organ of the males and in the ovariuterus of the females, both located in the abdominal cavity. The outer wider branch continues till the lateral wall of the cephalothorax where it climbs. Beyond this point it was impossible to identify its trajectory.

Following the dorso-lateral gonadal nerves, directly after the seventh metameric artery, a pair of bilateral nerves, known as the posterior nerves, emerges dorso-laterally as well (Fig. 2), and proceeds toward the abdomen. Given the small diameter of the dorsal cephalothoracic nerves and the inherent difficulty of maintaining them intact while removing the dorsal chitinous plates during dissection, it proved impossible to locate the structure innervated by this pair of nerves.

A pair of large diameter nerves $(145 \mu \mathrm{m})$, known as the pectinal nerves, emerges from the same neuromere as those cited above. These nerves are located ventrally, close to the eighth metameric artery (Figs. 1 and 2). The pectinal nerves extend caudally and ventrally from their point of origin and penetrate a small opening at the base of the pectens, a sensorial structures which they innervate.

Two pairs of lateral nerves emerge from the caudal region of the sub-esophageal ganglion of $B$. bonariensis, after the eighth metameric artery. One pair is more anterior and ventral; the other is more posterior and dorsal. They are known respectively as the third mesosomatic segmental nerves (diameter: $62.5 \mu \mathrm{m}$ ) and fourth mesosomatic segmental nerves (diameter: $72.5 \mu \mathrm{m}$ ) (Figs. 1 and 2 ). Although these nerves terminate in distinct and successive abdominal segments, i. e., the third and fourth mesosomatic segments, they have similar trajectories and terminate innervating corresponding structures in their respective metameres. They emerge from the sub-esophageal ganglion and follow a caudal direction; shortly after, they incline laterally, and the third mesosomatic segmental 
nerves pass in front of the first pair of book lungs, ascending the body wall at the division of the cephalothorax and the third segment of the mesosoma. The fourth mesosomatic segmental nerves pass in front of the second pair of book lungs and ascend the body wall between the third and fourth mesosomatic segments. Before reaching the area of the book lungs, they fork and emit both a thinner and a thicker branch. The former is an exclusively ventral branch implanted in the ventral longitudinal muscles and the base of the dorso-ventral muscles of the third and fourth mesosomatic segments. The thicker branch continues its lateral trajectory and innervates the book lungs of the corresponding segment, in this case the third and fourth, before ascending the lateral wall of the mesosoma (Fig. 1). It proved impossible to identify the area innervated by this dorsal extension.

It is possible to observe the ventral nervous cord raising from the caudal extremity of the subesophageal ganglion of $B$. bonariensis and fixed to it by a pair of connectives (Fig. 2).

\section{The ventral nervous cord}

The ventral nervous cord of $B$. bonariensis is formed by a set of 7 free ganglia linked longitudinally to each other and to the sub-esophageal ganglion by pairs of connectives of varying lengths (Fig. 1). The ventral cord is almost exclusively abdominal (opistosomal), despite its brief extension within the cephalothorax. It has three free ganglia located in the mesosoma and four in the metasoma, known respectively as $\mathrm{G}_{1}-\mathrm{G}_{7}$ (Fig. 1). With the exception of $\mathrm{G}_{7}$, each ganglion has two pairs of nerves emerging from its lateral surfaces. In each hemi-ganglion, there is an antero-dorsal nerve and a postero-ventral nerve, resulting in one pair of dorsal nerves and one of ventral nerves for each free ganglion.

Due to the reduced size of the ganglia, the close proximity of the nerves at their point of origin, and the fact that they are entwined for much of their initial trajectory, the presence of dorsal and ventral nerves in both halves of each ganglion only becomes apparent after their separation, at the ventral surface of the abdominal cavity of the animal. The ventral nerves of the free ganglia innervate bilaterally the predominantly ventral abdominal structures, while the dorsal nerves innervate dorsal structures, found in the same body division.
The $\mathrm{G}_{1}$ is located in the third segment of the mesosoma; it emits its pair of nerves caudally, which then innervates the fifth mesosomal segment (Fig. 1). The ventral component of this pair of nerves branches several times before finally entering the ventral longitudinal muscles of the segment. The dorsal component ascends the lateral wall of the animal body, passes over the pleural membrane separating the fourth and fifth segments, proceeds toward the latter segment, and emits a fine branch to the anterior region of the third pair of book lungs (Fig. 1).

The $G_{2}$ is found in the posterior half of the fifth segment (Fig. 1). Its nerves, which are oriented caudally, emit a series of small branches that, in a pattern similar to that observed in $\mathrm{G}_{1}$, innervate structures identical to those found in the anterior segment of the sixth segment of the mesosoma, e. g., such as the ventral longitudinal muscles and the book lungs (Fig. 1).

Located in the seventh segment of the mesosoma, the $\mathrm{G}_{3}$ emits its nerves frontward (Fig. 1), close to the division between the sixth and seventh mesosomatic segments. The pair of ventral nerves branches into the ventral longitudinal musculature of the seventh segment, while the dorsal components ascend the body wall at the division of the last two mesosomatic segments (Fig. 1).

The $\mathrm{G}_{4}, \mathrm{G}_{5}$, and $\mathrm{G}_{6}$ are located respectively in the first, second, and third segments of the metasoma (Fig. 1) and only innervate the musculature pertaining to the segment in which each is located. Due to the large quantity of muscle tissue found in these metasomal segments, both the ventral and dorsal nerve components exhibit a high degree of ramification.

The $G_{7}$ is located at the most anterior portion of the fourth metasomal segment (Fig. 1), occasionally being found at the division between the third and forth segment of the metasoma. This ganglion innervates the last three parts of the body of B. bonariensis: the fourth metasomal segment, the fifth metasomal segment, and the telson. When compared to the other ganglia of the ventral nervous cord, this one exhibits several marked differences; it is: much larger than the others, the only one with a metameric artery (located centrally and transverses dorso-ventrally the full extension of the ganglion), and the only one from which 5 pairs of nerves arise (Fig. 1). 
The first two pairs of nerves, called the fourth metasomal segmental nerves, exit laterally from the ganglion. They consist of one dorsal and one ventral pair. These nerve pairs divide into their dorsal and ventral components after a short distance and branch several times at the point where they enter the musculature of the fourth metasomal segment.

A third pair of nerves, of extremely reduced diameter, originating from $\mathrm{G}_{7}$, can be seen exiting, its caudal extremity dorsally. This thin pair of nerves penetrates the alimentary channel at the point where it meets the fourth metasomal segment, i. e., at the final portion of the mesenteron, and is known as the alimentary channel nerve (Fig. 1).

Two other pairs of nerves exit from the caudal extremity of the $\mathrm{G}_{7}$ : one ventral pair, for the fifth segment of the metasoma, known as the fifth metasomal segmental nerve, and one dorsal pair, for the telson, called the telsonic nerve (Fig. 1). Both nerve pairs exit $\mathrm{G}_{7}$ closely entwined and thusly transverse almost the entire length of the fourth metasomal segment. In the final third of the fourth metasomal segment, the ventral nerves separate from the dorsal nerves and curve laterally, crossing the division between the fourth and fifth metasomal segments and penetrating the musculature of the fifth metasomal segment, within which it branches intensely. The pair of dorsal nerves, for their part, transverse the fourth and fifth metasomal segments without branching. At the division of the fourth and the beginning of the fifth metasomal segments, the nerves adhere to each other for a short distance, forming a ring around the alimentary channel, which from this point on, turns ventrally and transverses the abdomen in the direction of the CNS, until opening at the anus (Fig. 1). In the last third of the fifth metasomal segment, the pair of nerves once again separates, forming a second ring around a dorso-ventral muscular strand located at the insertion point of the telson. Immediately thereafter the nerves once again join at the most caudal point of the fifth segment, penetrate the telson as a single branch, and then terminate innervating the venom glands, located within the vesicle of the telson (Fig. 1).

\section{DISCUSSION}

The results obtained from our study of $B$. bonariensis together with those from research carried out on the nervous system of other scorpion species permits the identification of a series of structures that should be included in a basic plan of the order Scorpiones. These are supposedly homologous structures, since they occupy highly similar or equivalent positions in relation to the other elements, as well as possessing the same specific features as other species studied (Kutsch $\&$ Breidbach, 1994; Schmitt, 1995). These are the median eye, lateral eye, rostral, cheliceral, pedipalpal, ambulatory, pectinal, and the lateral nerves of the free ganglia, and posterior nerves of the seventh free ganglion of the ventral nervous cord (McClendon, 1904; Buxton, 1917; Ch'eng-Pin, 1940; Henry, 1949; Babu, 1965; Lucas et al., 1965). However, there are structures in the nervous system of $B$. bonariensis for which it is evidently not possible to establish homology and which, therefore, require further study.

The accessory cheliceral nerves of the cheliceral ganglion of $B$. bonariensis may, due to their position, small calibre, and innervation, correspond to the finer cheliceral nerves found in: Tityus serrulatus (Lucas et al., 1965); one of the pairs of 2P nerves observed in Centruroides sp. (McClendon, 1904); the dorsal and internal pair of small calibre cheliceral nerves of Uroctonus mordax (Henry, 1949); and the accessory nerves 1 of Heterometrus fulvipes (Babu, 1965). In the same way, the accessory nerves of $B$. bonariensis may be compared to the nerves of other animals but based solely on the criterion of position, since identification of the structure that they innervate could not be made. Thus, this pair of nerves could represent the 4A nerve of Centruroides sp. (McClendon, 1904), the ventral and external pair of small calibre cheliceral nerves of Uroctonus mordax (Henry, 1949), and the two accessory nerves of Heterometrus fulvipes (Babu, 1965).

The esophageal nerves observed in B. bonariensis do not show any evident parallel any other nerves ascribed to the cheliceral ganglion of other scorpion species. Considering the single recurrent nerve found in Uroctonus mordax (Henry, 1949), completely separate origins are observed, since the latter emerges from an anterior ganglion, known as the frontal ganglion. When comparing the esophageal nerves of $B$. bonariensis with the intestinal nerves of Heterometrus fulvipes, the differences are even more marked, because the origin of the latter is on the posterior surface of the cheliceral gan- 
glion, from the sides of the stomodeum, over which this pair of nerves run (Babu, 1965).

As with the esophageal nerves of $B$. bonariensis, the aortic arch nerves cannot be satisfactorily compared with any structure of the cheliceral ganglion of any other species of scorpions. The lateral nerves of Euscorpius italicus (Police, 1903) and Heterometrus fulvipes (Babu, 1965) and the third pair of tegumentary nerves of Uroctonus mordax (Henry, 1949) emerge from the posterior surface of the cheliceral ganglion, above both the intestinal nerves and the circum-esophageal channel. Innervation of the stomach, and liver or pancreatic glands is attributed to the lateral nerves of the species referred to above (Bullock \& Horridge, 1965), while innervation of the lateral and posterior edges of the cephalothoracic carapace is attributed to the third pair of tegumentary nerves (Henry, 1949). Despite the posterior location of these nerves on the cheliceral ganglion, neither their position nor the innervation produced by them resemble that found for the pair of aortic nerves of $B$. bonariensis.

The localization of a large quantity of nervous tissue, originating from the above mentioned nerves, in the inner posterior wall of the aortic arches and extending dorso-posteriorly until the limit of the aortic arches and the beginning of the thoracic sinus respectively, suggests the presence of a neurohemal organ such as that identified in Euscorpius italicus. Called the Police organ, it consists of fibers from the intestinal and lateral nerves, originating in a group of neurosecretory cells that penetrate a vessel located posteriorly to the cheliceral ganglion (Bullock \& Horridge, 1965).

In $B$. bonariensis, the accessory pedipalpal nerves, as well as the accessory pedal nerves, can be found on the sub-esophageal ganglion. Structures occupying similar positions and producing the same type of innervation were observed in the cephalothoracic mass of Centruroides sp. (McClendon, 1904), Uroctonus mordax (Henry, 1949), and Heterometrus fulvipes (Babu, 1965). However, due to the inherent difficulty in localizating the accessory pedipalpal nerves and accessory pedal nerves, the variation in their number and position described in each one of the species, including $B$. bonariensis, does not allow the formulation of any hypothesis of homology when each nerve is considered individually.
In the latero-dorsal region of the sub-esophageal ganglion of B. bonariensis there were four pairs of metameric dorsal ambulatory nerves and one pair of ephemeral nerves. Four pairs of nerves, located in the same region, as well as a single, more posterior pair, of small diameter were reported in Centruroides sp. (McClendon, 1904) and Heterometrus fulvipes (Babu, 1965). Despite the great similarity between the five sets of $B$. bonariensis, and the nerves identified in the other two species, the resulting innervation is unknown in all three cases with the exception of the pair of ephemeral nerves from Heterometrus fulvipes, which innervates the dorsal muscles of the prosoma and the endosternite (Babu, 1965).

In the posterior region of the sub-esophageal ganglion of $B$. bonariensis two pairs of nerves can be seen directly after the ephemeral nerves, one dorso-lateral and the other ventro-lateral. Both unite to form a pair of genital nerves. A similar situation, with the presence of 2 pairs of nerves one dorsal and the other ventral, located after the ephemeral nerves can be seen only in Heterometrus fulvipes (Babu, 1965).

The pair of posterior nerves emerging immediately after the genital nerves in $B$. bonariensis does not have a clearly identified area of innervation. It is very difficult to trace a parallel between this and any nerve of the species described in the literature. However, this nerve may correspond to nerve 10A, described in Centruroides sp. (McClendon, 1904), due to the dorsal position of the latter in relation to the pectinal nerves, and its being found posteriorly in relation to the genital nerves.

The last two pairs of nerves found in the cephalothoracic mass of B. bonariensis correspond to the third and fourth mesosomatic segmental nerves. Nerves located in similar positions and innervating the same structures can be seen in Centruroides sp. (McClendon, 1904), Heterometrus fulvipes (Babu, 1965), and Tityus serrulatus (Lucas et al., 1965).

The single medium segmental nerve emerging from the ventral surface of the free ganglia of the ventral nervous cord, which has been described by some authors as a visceral nerve (Lankester et al., 1885; Bullock \& Horridge, 1965; Lucas et al., 1965; Hjelle, 1990) and which is also found in $B$. bonariensis is not really a nerve but rather a vessel originating from the ventral branch of the supra- 
neural artery that lies across the ganglia (Laurie, 1896).

In the seventh free ganglion of $B$. bonariensis there is a nerve similar to the alimentary channel nerve seen in Heterometrus fulvipes (Babu, 1965). Since it occupies the same position and innervates similarly, it could be considered identical to that of B. bonariensis.

From the above examples it can be seen that the nerves fitting least into the general plan of the nervous system of scorpions appear to be the esophageal and the aortic arch nerves. The remaining nerves, despite variations in many of the referredto species of scorpions, constitute good candidates for addition to the general plan of the order. However, to accomplish this a larger number of species belonging to different scorpion families must be examined in detail.

Acknowledgments - We would like to thank Drs. Ludwig Buckup and Georgina Bond Buckup for the use of their stereomicroscope. We are grateful to CAPES and the CNPq for their financial assistance.

\section{REFERENCES}

BABU, K. S., 1965, Anatomy of the nervous system of arachnids. Zool. Jb. Anat. Bd., 82: 1-154.

BULLOCK, T. H. \& HORRIDGE, G. A., 1965, Structure and function in the nervous system of invertebrates. W. $\mathrm{H}$. Freeman and Company, San Francisco, 2o vol., 1270p.

BUXTON, B. H., 1917, Notes on the anatomy of arachnids. J. Morphol., 29: 1-25.

CH'ENG-PIN, P., 1940, Morphology and anatomy of the Chinese scorpion Buthus martensi Karsch. In: G. A. Polis (ed.), 1990, The biology of scorpions. Standford University Press, Standford, 587p.

HENRY, L. M., 1949, The nervous system and the segmentation of the head in a scorpion (Arachnida). Microentomology, 14: 121-126.

HJELLE, J. T., 1990. Anatomy and morphology. In: G. A. Polis (ed.), The biology of scorpions. 587p. Stanford University Press, Standford, pp. 9-63
KUTSCH, W. \& BREIDBACH, O., 1994, Homologous structures in the nervous systems of arthropoda. Adv. Insect Physiol., 24: 1-113.

LANKESTER, M. A., BENHAM, W. B. S. \& BECK, E. J., 1885, On the muscular and endoskeletal systems of Limulus and Scorpio. Trans. Zool. Soc. London., 11: 311-384.

LAURIE, M., 1896, Notes on the anatomy of some scorpions, and its bearing on the classification of the order. Ann. Mag. Hist., Ser. 6, 17: 185-195.

LUCAS, S., EICHSTEDT, V. D. V. \& BÜCHERL, W., 1965, Sobre o sistema nervoso de Tityus serrulatus - Titinae Buthidae - Scorpiones. Mem. Inst. Butantan, São Paulo, 32: $15-26$

McCLENDON, J. F., 1904, On the anatomy and embryology of the nervous system of the scorpion. Biol. Bull., 8: $38-55$.

MILLOT, J. \& VACHON, M., 1949, Ordre des scorpions. pp. 386-436. In: P. P. Grassé (ed.), Traité de zoologie. Masson et Cie. Éditeurs, Paris, vol. 6, 979p.

POLICE, G., 1903, Sul sistema nervoso stomatogástrico del scorpione. In: K. S. Babu (ed.), 1965, Anatomy of the nervous system of arachnids. Zool. Jb. Anat. Bd., 82: 1-154.

POLIS, G. A., 1990, Introduction. In: G. A. Polis (ed.), The biology of scorpio, pp. 1-8.

RAMÓN Y CAJAL, S. \& DE CASTRO, F., 1972, Elementos de técnica micrográfica del sistema nervioso. Salvat Editores S.A., Barcelona, 283p.

ROMEIS, B., 1928, Guía-formulario de técnica histológica. Editorial Labor S.A., Barcelona, 722p.

ROOT, T. M., 1990, Neurobiology. In: G. A. Polis (ed.), The biology of scorpions. Standford University Press, Stanford, pp. 341-413.

SCHMITT, M., 1995, The homology concept - still alive. In: O. Breidbach \& W. Kutsch (eds.), The nervous systems of invertebrates: an evolutionary approach. Birkhäuser Verlag, Basel, pp. 159-179.

SISSOM, D. W., 1990, Systematics, biogeography and paleontology. In: G. A. Polis (ed.), The biology of scorpions. Standford University Press, Stanford, pp. 64-160.

STAHNKE, H. L., 1970, Scorpion nomenclature and mensuration. Ent. News, Philadelphia, 81: 297-316.

STOCKWELL, S. A., 1989, Revision of the phylogeny and higher classification of scorpions (Chelicerata). Ph. D. Dissertation, University of California, Berkeley, 413p. 